\title{
Discussion on the Detection Method of Lightning Protection of Expressway Toll Station
}

\author{
Jingcha Sun \\ Shandong Technical Center of Lightning Protection, Jinan Shandong, China \\ sunjingcha@163.com
}

Keywords: Expressway; Lightning detection; Toll station; Lightning protection.

\begin{abstract}
With the development of intelligent transportation, expressway toll station is more and more used electronic equipment, and electronic equipment constantly improve the degree of integration [1]. It also leads to the increasing lightning damage degree of expressway electronic equipment. Currently the expressway toll station although generally take the lightning protection measures, but there are still problems of lightning prevention. Therefore, we should strengthen the inspection and testing work on the expressway toll station lightning protection device, clear expressway toll station lightning detection of specific content, continuously improve lightning protection detection level, the installation of lightning protection device can play a effective role in the protection.
\end{abstract}

\section{Introduction}

Nearly 20 years, with the development of society, the rapid improvement of the electronics industry informatization level, caused by the thunder and lightning disaster economic loss and personnel casualty accidents are frequent, and multi frequency, serious harm, social influence big. Expressway toll station contains the communication, monitoring, charging and ventilation lighting system, these electrical and electronic systems constitute a powerful expressway mechanical and electrical systems. Especially the expressway electromechanical system without lightning protection facilities or facilities are not perfect caused the lightning invasion accidents and economic losses [2,3]. With the development of intelligent transportation, electronic devices are widely used and the degree of integration continues to improve, the harm degree of lightning on expressway electronic equipment will also increase. Despite the increased awareness of lightning protection, expressway toll stations have generally adopted a lightning protection measures, but due to the understanding of lightning protection is not in place, resulting in the expressway toll taken by lightning protection measures to some problems [4], and some do not meet the requirements of national standard, the lightning protection measures for too blindly. So we should strengthen on the expressway toll station lightning protection equipment inspection and testing work, the installation of lightning protection device can play an effective role in the protection.

\section{Existing Problems}

Grounding System Settings Do not Meet the Requirements of the Specification. There are many problems in the highway grounding system: for example, lightning grounding, signal grounding and safety grounding are independent grounding. Because of the expressway mechanical and electrical system of various types of buried metal pipeline laying more, it is difficult to achieve a safe distance between the ground and the ground, easily lead to the potential of lightning strike.

Outside the Laying of Metal Cable Has not Taken the Measures. Some outdoor installation (sometimes up to hundreds of meters) power supply line, suck as signal line and control line etc. not wearing a metal pipe buried underground, or the entrance of the building and metal tube missed at the ends. 
Setting of Surge Protection Device is not Scientific or not Comprehensive. Expressway electromechanical system power supply circuit and a communication control signal lines are different, the surge protector should be according to the signal characteristics and the physical location of the selected corresponding surge protector, but in the electromechanical system of the expressway of surge protection device selection is unreasonable or not matching, the lack of an overall concept. Sometimes a toll station, monitoring room is fitted with more than 10 kinds of models of different kinds of surge protection device (SPD), even some installed signal surge protector affected the normal operation of the system [5].

Surge Protector Assembly Problem. The widespread installation of surge protection device connected to both ends of the winding wire is too long and too small. When the lightning happened, the inductance of the wire itself is can not be ignored, the inductance prevent thunder and lightning current, high frequency fluent in, also will lead to voltage [6], and wire inductance and the material, wire diameter, the length, the bending degree, under the same material, the bending degree, length is shorter, and the line size is coarse the inductance quantity is small[7].

More of the Equipment Grounding, and Other Potential Problems. Lane weighing machine control cabinet, monitors, camera and guardrail are rod lane without equipotential processing. In charge of laying the island's power lines, signal lines and control lines, such as not wearing a metal tube or not for the treatment of such potential.

\section{Detection of External Lightning Protection Measures}

Toll booths buildings generally use the steel structure, a metal roof, should use the metal roof and other metal components as a lightning protector (no insulation cover), metal roof thickness should comply with the provisions of section 5.2.7, paragraph 2, of the literature [8]. When nonmetallic components on the roof, we should add air-termination system to protect it. When the steel structure of the metal column as down-conductor system should test metal column and a metal roof and ground potential connection parts of electrical connection. In addition, should do the following inspection and testing.

Contents should be checked: check ground flash device shall not be binding or suspension of all kinds of power lines, signal lines; check down-conductor system setting, materials, specifications, welding process, the corrosion protection measures; check off the assembly line and all kinds of signal lines, power lines between distance, horizontal spacing should not be less than $1 \mathrm{~m}$, cross spacing should not be less than $0.3 \mathrm{~m}$ [9]; view design and construction data, check the grounding form, connected to body material and anticorrosion measures, material specifications, cross-sectional area, thickness, buried depth, welding technology and down-conductor system connection; check meter system, charging system and toll booth lightning protection system whether to adopt a common ground.

The shed roof lightning detection: test device and each lead line of electrical connections; testing of electrical equipment, metal component and lightning protection device of the electrical connection; testing each root deflectors grounding resistance with disconnection card down-conductor system [10], each detection should disconnect card to measure the grounding device resistance; expressway electromechanical system should adopt the combined ground, AC grounding, security protection grounding, DC grounding, lightning protection and grounding of four kinds of grounding should share an assembling device, the grounding resistance to the minimum value determination; test weight system, charging system and charging lightning protection system common grounding resistance value.

\section{Detection of Internal Lightning Protection Measures}

Detection of Main Engine Room. Check the contents: first, the inspection of the equipment in the engine room position, should check in the machine room equipment from walls and columns, beams 
of distance is less than $1 \mathrm{~m}$; check the room within the external walls of reinforced should take electrical connection, check in the machine room of the metal door and window and the metal shielding net and buildings within the main reinforcement should be reliable electrical connections; check, room of the metal tube and groove, cable shielding layer should be approached with equal potential connection with; check in the machine room of power lines, signal lines installed SPD meets the requirements of the national standard.

Content detection: test room equipment cabinet, a metal shell of the grounding resistance; checking and measuring room set of equipotent connection with material specifications, testing equipotent connecting electrical and lightning protection device is connected with the.

Monitoring System Detection. Contents should be checked: check variable speed limit signs, variable information board, weather sensor, vehicle detector and monitoring camera probe is connected to the flash is effective within the scope of protection; inspection of transmission lines, distribution lines of laying, shielding, various signal lines, control signal line port set of SPD is in accordance with the design requirements; check monitoring system distribution lines installed in the lightning protection zones of different interface SPD meets the requirements of the national standard.

Content detection: line shielding layer should be in electrical communication and test the electrical connections; test vehicle detector, weather detector, a variable symbol display, chassis, and other metal shell and grounding device of electrical connection. Grounding resistance value of independent grounding device of test square camera.

Inspection of Charging System. Contents should be checked: check meter system, charging system and toll booth lightning protection system is the common ground; check toll booths, automatic railing, signal lamp, Lane guardrail, column, drive the camera support rod rack (), underground passage to the door, railings and other all metal structure parts and toll Island common earthing device of potential connections; check toll booths in the metal cabinet, a variety of mechanical and electrical equipment metal casing and toll booth reservation of equipotent connection terminal in electrical connection. Check into, out of the toll booths of distribution lines, signal lines in the lightning protection zone at the different interface of the installation of the SPD is in line with the requirements of the national standard.

Detection of the contents of the common grounding device to test the grounding resistance; test charging system of the equipment, cabinets and other electrical connections of the potential connection terminal board; test SPD grounding resistance, insulation resistance, leakage current.

Detection of Low Voltage Power Distribution System. Contents should be checked: inspection centers (stations) substation, power distribution room building lightning protection measures; check the distribution of real low-voltage distribution lines should adopt TN-S power supply mode; check is educed by a power distribution room of the distribution line cable should be shielded cables or wear of buried pipe laying; inspection of low-voltage distribution system installation of SPD meets the requirements of national standards.

Content detection, and outfield equipment connected to the buried cable shielding layer or wear line pipe should be at both ends of the earthed locally, and testing the grounding resistance; wear a shield or a line pipe should be in electrical communication, test the electrical connection.

\section{Summary}

In order to ensure the normal operation of the lightning protection device of expressway toll stations to prevent due to lightning protection device caused by the failure of the personal injury and equipment damage accidents, in accordance with the provisions of the relevant laws and regulations of the state and local regulations, expressway toll station lightning protection device should be regular safety inspection and testing system for maintenance, annual examination, discover a problem, timely rectification. 


\section{References}

[1] The China meteorological administration. Chinese meteorological disasters Yearbook 2011 [M]. Beijing: Meteorological Press, 2012.

[2] Zhang, W. J., Q. Meng, M. Ma, and Y. J. Zhang, 2011: Lightning casualties and damages in China from 1997 to 2009. Natural Hazards, 57, 465-476.

[3] Office of lightning protection management, China Meteorological Administration. Compilation of National Lightning Disaster in 2014 [R]. Beijing: China Meterological Administration, 2014.

[4] Feng, M. X., Analysis of lightning disaster on expressway [J]. Traffic information industry of China, 2006, (09): 51-52.

[5] Wen, B., Ma, Y., Li, B. S., etal. Simulation analysis of the over-voltage protection measures that protect the substation breaker from lightning invasion wave [J]. Journal of Science Technology and Engineering, 2013, 13 (2):87-91.

[6] QIE, X. S, ZHANG, Q. L, YUAN, T. etal. Lightning Physics [M]. Beijing: China Science Press, 2013 (In Chinese) .

[7] Wang, J. B., Dong, L. Y., Zhang, Z. W., etal. 220kV Transmission Line of Tangshan region Lightning Simulation [J]. Journal of Science Technology and Engineering, 2014,22:116-120.

[8] Ministry of housing and urban rural development of the people's Republic of China. (GB50057-2010) Design code for protection of structures against lightning [S]. Beijing: China Planning Press, 2011:55-58.

[9] China Meterological Administration. (QX/T 211-2013) Technical specification for inspection of lightning protection system on expressway facilities[S]. Beijing: China Meteorological Press, 2013:4-9.

[10]Xu, B. B., Yang, T. Q., Jin, C. L., etal. Analysis of Lightning Protection level to height sensitivity based on a variety of data[J].Journal of Science Technology and Engineering, 2013,13(9):94-98.

[11]Zheng, Y. F., Lin, Z. H., Wu, R. J., etal. Risk assessment of wind-powered meteorological disasters in Jiangsu Province [J]. Journal of Natural Disasters, 2012, 21( 4): 145-151 (In Chinese). 